\title{
Evaluation of Safety Culture in Institutional Chemical Analytical Laboratories in Oghara and Warri, Delta State, Nigeria
}

\author{
Godwin J. Birma, Silas A. Agaja, Joyce C. Ndu \\ Petroleum Training Institute, Effurun, Nigeria \\ Email: birma_jg@pti.edu.ng, agaja_sa@pti.edu.ng, issa_br@pti.edu.ng
}

How to cite this paper: Birma, G.J., Agaja, S.A. and Ndu, J.C. (2022) Evaluation of Safety Culture in Institutional Chemical Analytical Laboratories in Oghara and Warri, Delta State, Nigeria. Open Journal of Safety Science and Technology, 12, 17-29. https://doi.org/10.4236/ojsst.2022.121002

Received: October 7, 2021

Accepted: January 10, 2022

Published: January 13, 2022

Copyright $\odot 2022$ by author(s) and Scientific Research Publishing Inc. This work is licensed under the Creative Commons Attribution International License (CC BY 4.0).

http://creativecommons.org/licenses/by/4.0/

\begin{abstract}
This study was aimed at evaluating safety culture in 20 chemical analytical laboratories in Oghara and Warri, Delta state. This was achieved through a determination of the safety performance between tertiary education chemical laboratories and industrial laboratories, private and government-owned laboratories, and technical and non-technical labs. The method employed in carrying out this study was the use of a 5-point Likert scale questionnaire and a standard checklist. Comparison done between private and government-owned laboratories using t-test showed that safety culture of private-owned laboratories, irrespective of whether industrial or tertiary education, were more significant $(P<0.05)$ than that of government-owned laboratories. Analysis of t-test for the survey indicated no significant difference between tertiary education and industrial laboratories $(\mathrm{P}>0.05)$, with a mean value of 3.69798 for tertiary education laboratories and 3.62842 for industrial laboratories. Analysis of t-test also indicated $\mathrm{P}<0.05$ for technical $(\mathrm{M}=75.00)$ and non-technical $(\mathrm{M}=56.11)$ tertiary education laboratories. However, further t-test analysis indicated that there is a significant difference between safety performance in tertiary education laboratories and industrial laboratories $(\mathrm{P}$ $<0.05$ ). The conclusion is that tertiary education chemical analytical laboratories have a high level of safety culture with an overall mean of 67.90 than industrial chemical analytical laboratories with an overall mean of 54.50. It is recommended that laboratories should establish an internal review process of incidents and corrective actions with the departmental safety committee and provide periodic safety seminars on lessons learned from incidents. A strong and effective safety management system should also be implemented in all analytical laboratories.
\end{abstract}

\section{Keywords}

Safety, Culture, Industry, Institution, Safety 


\section{Introduction}

According to the International Nuclear Safety Group (INSAG4); "Safety culture is that assembly of characteristics and attitudes in organizations and individuals, which establishes as an overriding priority". This definition highlights both structural and attitudinal Safety Culture [1] [2] [3] [4]. According to the Occupational Safety and Health Administration (OSHA, 2015) [5] in strong safety culture, "Everyone feels responsible for safety and pursues it on a daily basis, employees go beyond the "call of duty" to identify unsafe conditions and behaviors, and intervene to correct them".

With the promulgation of the Occupational Safety and Health Administration (OSHA) laboratory standard (29 CFR 1910.1450), a Culture of Safety consciousness, accountability, organization, and education has developed in industrial, governmental, and academic laboratories. Safety and training programs have been implemented to monitor the handling of chemicals from ordering to disposal and to train laboratory personnel in safe practices [5] [6].

Safety culture is a critical dimension in safety, ensuring success or causing failure in organizations and numerous studies in recent years have identified it as major issue requiring regulatory interventions [6]-[11].

Laboratories are associated with a variety of possible hazards which could lead to risk of fire or some chemical substances can be carcinogenic, toxins, irritants, corrosives, sensitizers, as well as agents that act on the blood system or damage the lungs, skin, eyes, or mucous membranes, mutagens, embryotoxic. It is important to keep in mind that chemicals can exhibit more than one hazard or combinations of several hazards because several factors can influence how a chemical will behave [12].

Biological hazard refers to biological substances that pose a threat to the health of living organisms, primarily that of humans. Infectious biological hazards like viruses, bacteria, fungi or parasites or their products can cause human diseases when they are inhaled, ingested, contact skin or eye [13]. Ergonomic hazards from Laboratory activities like pipetting of fluid, prolonged standing and bending, poor workspace and positions pose risk of injury to the musculoskeletal system [14] [15].

Physical agents such as needles, knives, broken bottles can lead to hazard of pricks and cut; electrical equipment and improper wiring can lead to electrocution; wet, uneven or damaged floors surfaces, trailing cables can cause hazards of slips and trips; noise and vibration produced from equipment such as centrifuges and stirrers can cause hearing loss and stress, entanglement of clothes, hair or fingers in rotating equipment such as centrifuges and mixers can cause bodily injury [16].

Psychosocial hazards are stress, the threat of danger, discrimination, constant low-level noise, violence, or bullying in the workplace environment. This can involve how workers interact with other workers and/or emotional responses workers have that negatively impact a worker's productivity or effectiveness [16]. 
Hazards are an intrinsic property of a substance or condition and cannot truly be removed, however, it is good to identify them so that appropriate controls can be implemented and the associated risk from the hazard can be reduced or mitigated. The active involvement of senior management in the health and safety system is very important and to identify the general attributes of strong or good safety culture [17] [18].

Therefore, management leadership is a key factor to high level of safety performance. A laboratory with high level of management commitment will likely have very low lost-time injury and vice versa [19]. It is important to conduct thorough hazard and risk analysis before beginning an experiment protocol or manufacturing processes [20] [21]. Positive safety culture would lead to Lower Absenteeism, Lower Wage Bills, Reduced Repairs and Re-Working, Happier Workforce, Lower Staff Turnover, Reduced Risk of Fines, Reduced Insurance Claims, Reduced Insurance, Improved Productivity, Quality and Profitability and more Satisfied Clients and Stakeholders [22].

This research work is to evaluate the level of safety performance and improved the level of safety consciousness in twenty (20) analytical laboratories in Oghara and Warri, Delta State, Nigeria. This is to enhance productivity, quality and profitability, reduce repairs, reworking and insurance claim, thereby providing a safe working environment (for workers and researchers) resulting in low accident/incident occurrence and improving job motivation as well as job satisfaction.

\section{Materials and Methods}

\subsection{Sample Size and Population Size}

A total number of twenty (20) analytical laboratories (ten industrial and ten tertiary educations) were carefully identified and selected for this research work. The population size of 200 members of staff and/or students were selected randomly for this study for the administration and completion of the safety culture questionnaires. Questionnaires were administered to ten (10) respondents at each of the twenty (20) sampling locations of the industrial and academic laboratories.

The method adopted for carrying out this work was the use of questionnaires and checklist. The questionnaire consists of close-ended questions which was self-administered and distributed to ten (10) employees in each laboratory.

The checklist contained seventy-seven (77) questions which were used to check the organizations performance to safety culture through inspections, and interview methods.

\subsection{Safety Culture in Analytical Laboratories Questionnaire}

The questionnaire consists of thirty-five (35) modified close-ended Likert Scale questions adapted from OSHA, New South Wales Government Questionnaire and Safety Climate Assessment Questionnaire [23] [24] [25]. Section A of the 
questionnaire covered the demographic information, while section B focuses on specific area of general safety culture in the laboratory which includes hygiene factors, training and competence, safety reporting and investigation, work duties/pressure, management commitment, safety communication, and emergency preparedness and response.

\subsection{Safety Culture in Analytical Laboratories Checklist}

The Checklist for safety culture in analytical laboratories contains seventy-seven (77) modified questions which were carefully answered by inspecting the laboratories and interviewing personnel where necessary. The checklist was adopted from the European Agency for Safety at work [26]. The 77 questions are distributed through 9 parts of the checklist. These 9 parts represent the core elements of safety culture as documented in OSHA standards. The parts include; General laboratory safety, information for workers, chemical safety, biological safety, hygiene, emergency procedure, personal protective equipment, hazardous waste handling, and housekeeping.

\subsection{Method of Data Analysis}

The data collected from the checklist and survey was compiled and assigned codes. Descriptive statistics were used to analyze the data using Microsoft Excel 2019. Further statistical analysis used includes t-test and one-way analysis of variance (One-Way ANOVA) in order to arrive at reasonable and reliable conclusions.

\section{Results and Discussion}

Table 1 represents the percentage scores obtained for the various variables used to assess the average safety performances of the 10 selected tertiary education chemical laboratories. The criteria variables used are; general laboratory, information for workers, chemical safety, biological safety, hygiene, emergency procedure, personal protective equipment, hazardous waste management, and housekeeping. The result shows that the emergency procedure and biological safety hazards scored far below averaged in Lab 1 with $26 \%$ and $27 \%$ respectively. Similarly, personal protective equipment in addition to poor emergency arrangement had the lowest scores in Lab 2 with 33\% and 34\% respectively. However, housekeeping had the highest score of $96 \%$ in Lab 6 followed by $95 \%$ in housekeeping and general Laboratory safety in Lab 7 and Lab 6 respectively.

Table 2 and Figure 1 present the average satisfactory and unsatisfactory level of safety performance of the 10 tertiary laboratories studied. The result of the average safety performance showed poor performances in the first laboratory (Lab 1) and Second Laboratory (Lab 2) with satisfactory scores of $46 \%$ and $48 \%$ respectively. The tenth (Lab 10) and eighth (Lab 8) Laboratories performed excellently well with the highest level of satisfactory performance scores of $82 \%$ and $81 \%$ respectively. Generally the Laboratories 3 to 10 performed very well 
Table 1. Percentage level of safety performance for tertiary education laboratories.

\begin{tabular}{ccccccccccc}
\hline Safety Variables & Lab 1 & Lab 2 & Lab 3 & Lab 4 & Lab 5 & Lab 6 & Lab 7 & Lab 8 & Lab 9 & Lab 10 \\
\hline General Laboratory Safety & 50 & 51 & 80 & 78 & 89 & 95 & 88 & 84 & 82 & 87 \\
Information for Workers & 57 & 54 & 78 & 70 & 80 & 86 & 86 & 82 & 82 & 82 \\
Chemical Safety & 51 & 53 & 77 & 69 & 84 & 84 & 82 & 78 & 79 & 78 \\
Biological Safety & 27 & 67 & 70 & 66 & 40 & 49 & 68 & 77 & 84 & 77 \\
Hygiene & 53 & 53 & 77 & 74 & 73 & 82 & 77 & 85 & 78 & 87 \\
Emergency Procedure & 26 & 34 & 71 & 68 & 76 & 74 & 78 & 79 & 74 & 79 \\
Personal Protective Equipment & 44 & 33 & 74 & 65 & 51 & 68 & 69 & 86 & 78 & 86 \\
Hazardous Waste & 48 & 40 & 68 & 62 & 64 & 73 & 59 & 84 & 83 & 86 \\
Housekeeping & 60 & 44 & 76 & 80 & 92 & 96 & 95 & 78 & 80 & 78 \\
\hline
\end{tabular}

Table 2. Average safety performance for tertiary education laboratories.

\begin{tabular}{|c|c|c|c|c|c|c|c|c|c|c|}
\hline \multirow{2}{*}{$\begin{array}{l}\text { Level of Safety } \\
\text { Performance }\end{array}$} & \multicolumn{10}{|c|}{ Tertiary Education Laboratories } \\
\hline & Lab 1 & Lab 2 & Lab 3 & Lab 4 & Lab 5 & Lab 6 & Lab 7 & Lab 8 & Lab 9 & Lab 10 \\
\hline Satisfactory & 46 & 48 & 75 & 70 & 72 & 79 & 78 & 81 & 80 & 82 \\
\hline Unsatisfactory & 54 & 52 & 25 & 30 & 28 & 21 & 22 & 19 & 20 & 18 \\
\hline
\end{tabular}

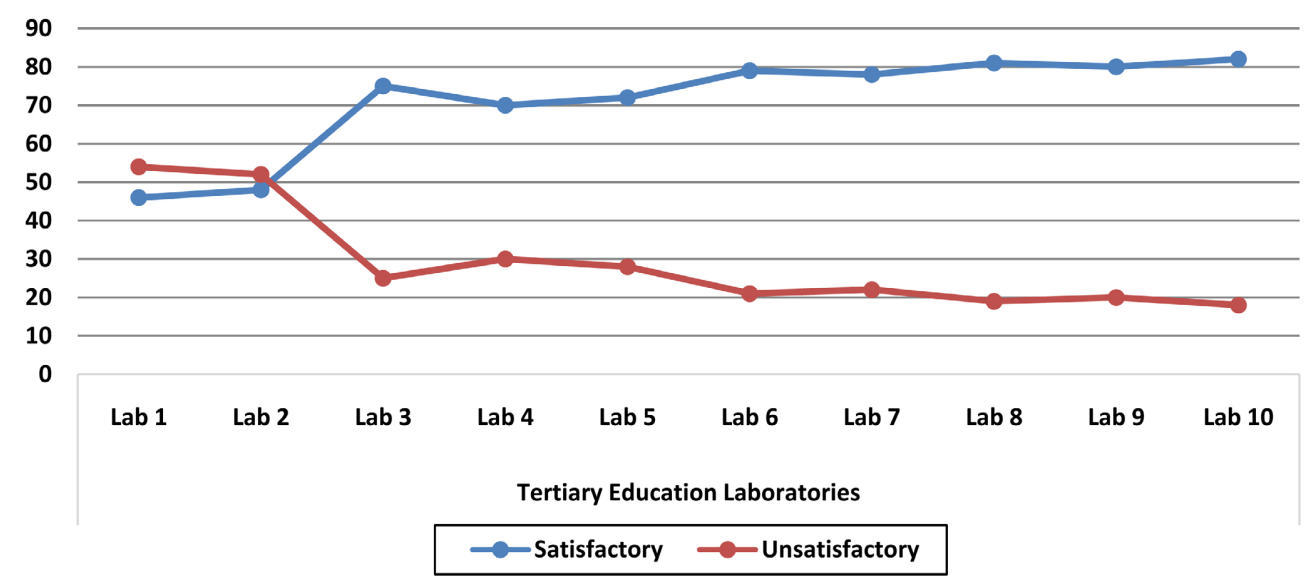

Figure 1. Level of safety culture in tertiary education laboratories.

with satisfactory performance scores far above average (50\%) as shown in Table 2 and Figure 1.

The result of the Analysis of Variance (ANOVA) for Academic Laboratories showed that the value of the degree of freedom calculated $\left(\mathrm{F}_{c a l}\right)$ is greater than $\mathrm{F}_{\text {critical }}(15.873>1.999)$ and $\mathrm{P}$-value is less than $0.05(\mathrm{P}<0.05)$. This shows that there is significant difference in safety performance of the 10 tertiary education laboratories. This confirms to the low average scores of $46 \%$ and $48 \%$ in Lab 1 and Lab 2 respectively, against the high values in other laboratories especially Lab 10 and Lab 8. 
Therefore, a further analysis may be necessary, by sectioning the tertiary education laboratories into government owned tertiary education laboratories and private owned tertiary education laboratories in order to ascertain a reasonable conclusion.

\subsection{Determination of Safety Performance in Industrial Laboratories}

Table 3 represents the percentage level of safety performance for the variables used to determine the average safety performances of the ten (10) Industrial chemical laboratories. The same variables were used as in the tertiary Laboratories as shown below. The result of the safety performance study in Industrial Laboratory showed that there were problem with inadequate worker information, especially in Lab 6 and Lab 5 with the lowest percentages of 34 and 37 respectively. Another potential area of concern as identified in study is the emergency procedure preparedness, especially for Lab 5 and Lab 7 both with score of $39 \%$. High positive culture performances were observed in housekeeping (92\% in Lab 9 \& 10) and general safety of the Laboratory (91\% in Lab 9) as shown in Table 3.

Table 4 and Figure 2 show the average satisfactory and unsatisfactory level of safety performance of the 10 industrial laboratories experimented. The result from the table shows that four laboratories ( $\mathrm{Lab} 3,7,4$ \& 5) had satisfactory performance level below average (50\%) with scores of $41 \%, 42 \%, 46 \%$ and $49 \%$ respectively. The highest score of $75 \%$ goes to Lab 9 whose safety performance is high and the industrial Laboratories.

Based on the analysis of variance (ANOVA) result obtained, the value of Freedom Ratio calculated $\left(\mathrm{F}_{\text {cal }}\right)$ is greater than $\mathrm{F}_{\text {critical }}(13.1511>1.991)$ and $\mathrm{P}$-value is less than $0.05(\mathrm{P}<0.05)$. Therefore there is a significant difference in safety performance of the 10 industrial laboratories selected for this study. This is in line with wide ranges of average ( $41 \%$ to $75 \%)$ seen in Table 4 . Therefore, a

Table 3. Percentage level of safety performance for industrial laboratories.

\begin{tabular}{|c|c|c|c|c|c|c|c|c|c|c|}
\hline Safety Variables & Lab 1 & Lab 2 & Lab 3 & Lab 4 & Lab 5 & Lab 6 & Lab 7 & Lab 8 & Lab 9 & Lab 10 \\
\hline General Laboratory Safety & 66 & 54 & 46 & 52 & 50 & 48 & 51 & 65 & 91 & 83 \\
\hline Information for Workers & 57 & 50 & 49 & 43 & 37 & 34 & 48 & 56 & 60 & 54 \\
\hline Chemical Safety & 71 & 46 & 46 & 58 & 48 & 48 & 37 & 64 & 80 & 64 \\
\hline Biological Safety & 40 & 46 & 47 & 47 & 35 & 34 & 39 & 57 & 80 & 80 \\
\hline Hygiene & 71 & 49 & 54 & 48 & 42 & 42 & 50 & 57 & 51 & 47 \\
\hline Emergency Procedure & 60 & 46 & 50 & 56 & 39 & 39 & 39 & 54 & 89 & 84 \\
\hline Personal Protective Equipment & 58 & 49 & 55 & 88 & 47 & 47 & 47 & 59 & 51 & 73 \\
\hline Hazardous Waste & 40 & 47 & 46 & 42 & 41 & 43 & 49 & 53 & 84 & 84 \\
\hline Housekeeping & 60 & 55 & 49 & 54 & 39 & 37 & 51 & 52 & 92 & 92 \\
\hline
\end{tabular}




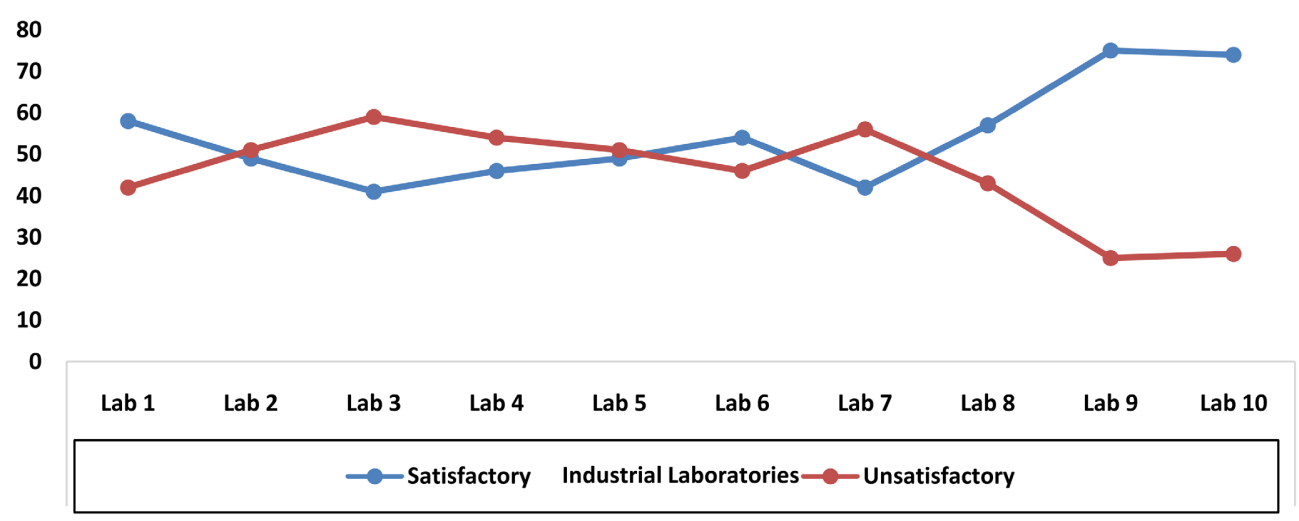

Figure 2. Level of safety culture in industrial chemical analytical laboratories.

Table 4. Average safety performance for industrial laboratories.

\begin{tabular}{ccccccccccccc}
\hline \multirow{2}{*}{$\begin{array}{c}\text { Level of Safety } \\
\text { Performance }\end{array}$} & Lab 1 & Lab 2 & Lab 3 & Lab 4 & Lab 5 & Lab 6 & Lab 7 & Lab 8 & Lab 9 Lab 10 \\
\cline { 2 - 11 } & 58 & 49 & 41 & 46 & 49 & 54 & 42 & 57 & 75 & 74 \\
Satisfactory & 58 & 51 & 59 & 54 & 51 & 46 & 56 & 43 & 25 & 26 \\
Unsatisfactory & 42 & & & & & & & & & & &
\end{tabular}

further analysis may be necessary, by sectioning the industrial laboratories into government-owned industrial laboratories and private-owned industrial laboratories in order to ascertain a reasonable conclusion.

\subsection{Comparison between Industrial and Tertiary Education Laboratories}

The t-test analysis was used to ascertain the significant difference in the level of safety performance between tertiary education and industrial laboratories, at $5 \%$ level of significance. The evidence from the student $t$-test result indicated that there is significant difference between safety performance of academic laboratories and industrial laboratories, since the value of $\mathrm{P}(\mathrm{T} \leq \mathrm{t})$ two-tail is less than 0.05 value of $P,(P<0.05)$. This means that there is significant difference between the two groups of laboratories. However, the difference in the mean performance can aid a justified conclusion, as the result of the tertiary laboratories has an average of $67.9 \%$, while $54.5 \%$ was obtained for industrial laboratories. This result contrary to what was obtained in previous research done by [20] Imke et al., (2016). They showed that commitment to health and safety programs was high in company laboratories. They observed that industrial laboratories recognize both their moral responsibility and their own self-interest in developing the best possible safety programs, extending them not just to employees but also to contractors. They also observed that industrial laboratory environment provides strong corporate structure and discipline for maintaining a well-organized safety program where safety culture is thoroughly understood, respected, and enforced from the highest level of management down (Figure 3). 


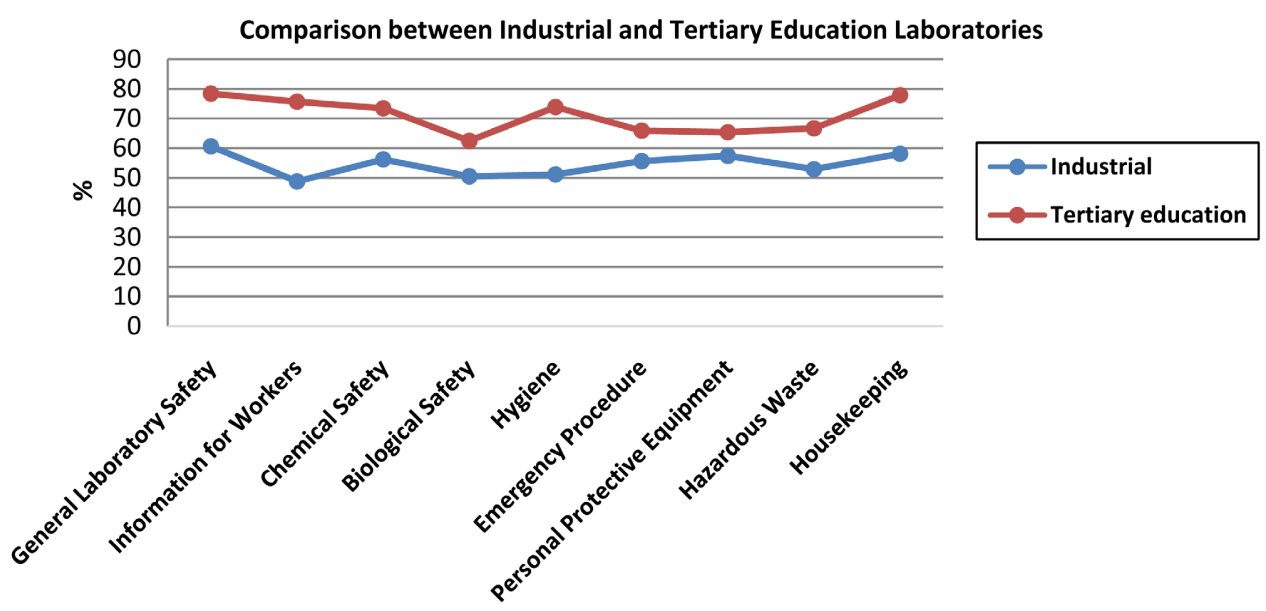

Figure 3. Percentage level of safety culture in industrial and tertiary education laboratories.

Another researcher [3] Guldenmund (2010) also suggested that industrial laboratory workers readily accept training as a benefit to their safety, or they are more compliant with safety regulations regardless of its perceived usefulness in improving safety.

\subsection{Demographic Information of Respondents}

The Demographic Information of Respondents as presented in Table 5 shows $42 \%$ are males and $58 \%$ are females, consisting of $35 \%$ workers and about $65 \%$ of students/Interns. About $77 \%$ of the respondents have spent $1-5$ years in the laboratory, 13\% have spent 6 - 10 years and only $10 \%$ have spent between $11-15$ years. $10 \%$ of the respondents were below 20 years old, $54 \%$ between $21-30$ years of age; $19 \%$ between 31 - 40 years, $15 \%$ between 41 - 50; and only $6 \%$ between 51 - 60 years old.

From the information in Table $6,45 \%$ of males and $55 \%$ of females, this is made up of $42 \%$ workers and about $58 \%$ of interns. About $71.5 \%$ of the respondents have spent 1 - 5 years in the laboratory, 16.5\% have spent 6 - 10 years, 7\% between 11 - 15 years, 2.5\% between 1620 years, and 2.5\% have spent more than 20 years in the laboratory. $13 \%$ of the respondents were below 20 years old, $48 \%$ between 21 - 30 years of age; $21 \%$ between 31 - 40 years, 14\% between 41 - 50; and only $4.5 \%$ between $51-60$ years old.

\subsection{Workers and Students' Perception in Tertiary Education Laboratories}

Descriptive statistics were used to measure the variables of safety culture that is perceived to be the most important among employees in the laboratories. Workers and students' opinion on safety culture were measured by seven variables (hygiene factors, training and competence, safety reporting and investigation, work duties/pressure, management commitment, safety communication, and emergency preparedness and response) which was computed to obtain the average opinion for each of the tertiary education laboratories. From the result 
Table 5. Percentage demographic distribution of respondents in tertiary education laboratories.

\begin{tabular}{|c|c|c|c|c|c|c|c|}
\hline \multicolumn{2}{|c|}{ Gender } & \multicolumn{2}{|c|}{$\begin{array}{l}\text { Category of } \\
\text { Respondents }\end{array}$} & \multicolumn{2}{|c|}{$\begin{array}{l}\text { Length } \\
\text { of Service } \\
\text { (In Years) }\end{array}$} & \multicolumn{2}{|c|}{$\begin{array}{c}\text { Age } \\
\text { Group } \\
\text { (In Years) }\end{array}$} \\
\hline Male & 42 & Worker & 35 & $1-5$ & 77 & $<20$ & 10 \\
\hline \multirow[t]{4}{*}{ Female } & 58 & Student/Intern & 65 & $6-10$ & 13 & $21-30$ & 54 \\
\hline & & & & $11-15$ & 10 & $31-40$ & 19 \\
\hline & & & & & & $41-50$ & 15 \\
\hline & & & & & & $51-60$ & 6 \\
\hline
\end{tabular}

Table 6. Percentage distribution of respondents in industrial laboratories.

\begin{tabular}{|c|c|c|c|c|c|c|c|}
\hline \multicolumn{2}{|c|}{ Gender } & \multicolumn{2}{|c|}{$\begin{array}{l}\text { Category of } \\
\text { Respondents }\end{array}$} & \multicolumn{2}{|c|}{$\begin{array}{c}\text { Length } \\
\text { of Service } \\
\text { (In Years) }\end{array}$} & \multicolumn{2}{|c|}{$\begin{array}{c}\text { Age } \\
\text { Group } \\
\text { (In Years) }\end{array}$} \\
\hline Male & 45 & Worker & 42 & $1-5$ & 71.5 & $<20$ & 13 \\
\hline \multirow[t]{4}{*}{ Female } & 55 & Intern & 58 & $6-10$ & 16.5 & $21-30$ & 48 \\
\hline & & & & $11-15$ & 7 & $31-40$ & 21 \\
\hline & & & & $16-20$ & 2.5 & $41-50$ & 14 \\
\hline & & & & $>20$ & 2.5 & $51-60$ & 4.5 \\
\hline
\end{tabular}

obtained, Lab 10 and Lab 4 were perceived high with mean of 4.334 and standard deviation of 0.8390 , and 4.0086 with standard deviation of 0.8024 . While Lab 1 was perceived as slightly low with mean score of 3.0857 and standard deviation of 0.8904 . As indicated by the survey results, the mean of workers and students' perception on safety culture in the 10 tertiary education laboratories were between the ranges of 3.0857 to 4.3343 , thus indicating a slight mixture of "Strongly Disagree/Disagree" to "Strongly Agree/Agree".

\subsection{Workers and Students' Perception in Industrial Laboratories}

Descriptive statistics were also used to measure the variables of safety culture that is perceived to be the most important among workers in the 10 industrial laboratories. Workers and students' opinion on safety culture were measured by seven variables, which was computed to obtain the average opinion for each of the industrial laboratory. From the result obtained, Lab 7 was perceived slightly high with mean of 3.7686 and standard deviation of 0.7800 . While Lab 10 was perceived as slightly low with mean score of 3.5357 and standard deviation of 0.6393. As indicated by the survey results, the mean of workers and students' perception on safety culture in the 10 industrial laboratories were between the ranges of 3.5357 to 3.7686, thus indicating a higher mixture of "Strongly Disagree/Disagree" to "Strongly Agree/Agree" than the tertiary education laboratories. 


\subsection{Comparison between Tertiary Education and Industrial Laboratories}

The t-test Analysis for Comparing Respondent's Perception was used to ascertain the significant difference in the opinion of the workers and students between tertiary education and industrial laboratories, at $5 \%$ level of significance. Evidence from the test result indicated that there is no significant difference between safety performance of tertiary education laboratories and industrial laboratories, since the value of $\mathrm{P}(\mathrm{T} \leq \mathrm{t})$ two-tail is greater than 0.05 value of $\mathrm{P}(\mathrm{P}>$ $0.05)$. Hence, null hypothesis was accepted and the alternate rejected. The conclusion is that there is no significant difference in respondents' perception on safety culture between the two groups of laboratories. Although, the mean value of the academic ( $\mathrm{M}=3.69798)$ respondents exceeds that of the industrial respondents $(M=3.62842)$ slightly. However, the result of our observation demonstrated that the value of the mean is not enough to conclude that tertiary education laboratories are better than industrial laboratories. This is conformity with research done by [27], they observed that laboratory safety perceptions were similar between respondents from tertiary education and industrial laboratories and $90 \%$ of respondents or more agreed that their laboratory was a safe place to work. Furthermore, the majority of the respondents stated that safety in their laboratory took precedence over all other laboratory priorities.

\section{Conclusion}

Institutionalizing positive safety culture in any organisation is a major contributing factor for overall safety performance. The results from the assessment methods (questionnaire and checklist) used in this study showed that management commitment in form of supervision was high in tertiary education laboratories. It was also observed that experiment manuals, waste management, personal protective equipment, and housekeeping are of more priorities in academic laboratories than in industrial laboratories. Statistical test results discovered that the level of safety culture was significantly different among the tertiary education analytical laboratories as well as the industrial analytical laboratories. Finally, it is concluded that safety culture is more significant in tertiary education chemical laboratories than industrial laboratories.

\section{Recommendations}

1) Laboratory personnel should exercise a duty of care by working in a safe and efficient manner, having regard to their personal safety and the safety of other workers as well as the public.

2) The lines of authorities in any analytical Laboratory should demonstrate commitment to safety according to clause 5 of ISO45001[28] by establishing laboratory health and safety Management system, safety policy and objectives as well as institute evaluation and monitoring processes to ensure that they are met.

3) There should be periodic conduct of safety audit to assess the effectiveness 
of the health and safety management system and other measures.

4) Hazards identification, classification and analysis procedures should be established and implemented in all new laboratory work, especially laboratory research.

5) Adopt a personal credo: the "Safety Ethic" — value safety, work safely, prevent at-risk behavior, promote safety, and accept responsibility for safety.

6) Establish and maintain an Incident Reporting System, an Incident Investigation System, and an Incident Database that should include not only employees but also students.

7) Safety supervisors should be competent and adequately empowered to be able to access and share legislation, codes and standards, plan and implement safety requirements, monitor and report safety performance or non-compliance.

\section{Conflicts of Interest}

The authors declare no conflicts of interest regarding the publication of this paper.

\section{References}

[1] International Atomic Energy Agency (2011) Regulatory Oversight of Safety Culture in Nuclear Installations. TECDOC DD1070.

[2] International Atomic Energy Agency (1991) Safety Cultures [Safety Series No. 75-INSAG-4]. A Report, the International Nuclear Safety Advisory Group, Vienna.

[3] Guldenmund, F.W. (2010) Understanding and Exploring Safety Culture. Delft University, Delft.

[4] Schobel, M., Lostermann, A., Lasalle, R., Beck, J. and Manzey, D. (2017) Digging Deeper! Insights from Multi-Method Assessment of Safety Culture in Nuclear Power Plant Based on Schein's Culture Model. Safety Science, 95, 38-49. https://doi.org/10.1016/j.ssci.2017.01.012

[5] Occupational Safety and Health Administration (OSHA) (2015) OSHA Publications on Laboratory Safety. Department of Health and Human Services, Centers for Disease Control and Prevention.

http://www.osha.gov/pls/publications/publication.athruz?pType $=$ industry\&pID $=11$ $\underline{7}$

[6] University of South Florida (2019) Laboratory Safety Rules, Procedures and Practices.

https://www.usf.edu/arts-sciences/departments/chemistry/documents/laboratory-safet y-rules-and-agreementv.sp2019.pdf\&ved=2ahUKEwjP1IaE96_iAhUaThUIHcooA9E QFjAAegQIARAB\&usg=AOvVaw3z1npxpYHGJh6xeHN4O3hK

[7] Occupational Safety and Health Administration OSHA (2014) Bloodborne Pathogens 2014 .

https://www.osha.gov/pls/oshaweb/owadisp.show_document?p_table=STANDARD S\&p_id=10051

[8] Ayi, H. and Hon, C. (2018) Safety Culture and Safety Compliance in Academic Laboratories: A Canadian Perspective. Journal of Chemical Health and Safety, 25, 6-12. https://doi.org/10.1016/j.jchas.2018.05.002

[9] Lee, T.R., MacDonald, S.M. and Coote, J. (2017) Perceptions of Risk and Attitudes 
to Safety at a Nuclear Processing Plant. In: 4th Conference on European Technology and Experience in Safety Analysis and Risk Management, Society for Risk Assessment (Europe), Rome.

[10] Antonsen, S., Nilsen, M. and Almklov, P.G. (2017) Regulating the Intangible. Searching for Safety Culture in the Norwegian Petroleum Industry. Safety Science, 92, 232-240. https://doi.org/10.1016/j.ssci.2016.10.013

[11] Antonsen, S. (2009) Safety Culture: Theory, Method and Improvement. Ashgate Publishing, Farnham.

[12] Cornell, E.H.S. (2018) Laboratory Safety Manual and Chemical Hygiene Plan. Laboratory and Research Safety, Cornell University, Ithaca, 7-9.

http://sp.ehs.cornell.edu/lab-research-safety/laboratory-safety-manual/pages/ch8.as px

[13] Center for Disease Control and Prevention (2014) Biosafety in Microbiological and Biomedical Laboratories.

http://www.cdc.gov/biosafety/publications/bmbl5/index.htm

[14] University of Alberta, Environment Health and Safety (2019) Hazard Management. http://www.ualberta.ca/environment-health-safety/hazardmanagement/what-are-ha zards/ergonomicse-mynt

[15] The University of Chicago (2016) Environmental Health and Safety "Ergonomics".

[16] National Institute for Occupational Safety and Health (2018) Promoting Productive Workplace through Safety and Health Research. NIOSH Publications and Products. https://www.cdc.gov/niosh/surveyreports

[17] Warszawska, K. and Kraslawski, A. (2016) Method for Quantitative Assessment of Safety Culture. Journal of Loss Prevention in the Process Industries, 42, 27-34. https://doi.org/10.1016/j.jlp.2015.09.005

[18] Do-Nascimento, C.S., Andrade, D.A. and De Mesquita, R.N. (2017) Psychometric Model for Safety Culture Assessment in Nuclear Research Facilities. Nuclear Engineering and Design, 314, 227-237. https://doi.org/10.1016/j.nucengdes.2017.01.022

[19] Agaja, S.A. (2012) Appraisal of Safety Climate in Government and Private Analytical Laboratories in Warri, Delta State, Nigeria. International Journal of Scientific and Technology Research, 1, 34-35.

[20] Imke, S., Huang, D.Y.Q., Ellis, O., Gibson, J.H. and Wayne, N.L. (2016) Laboratory Safety Attitudes and Practices: A Comparison of Academic, Government, and Industry Researchers. Journal of Chemical Health and Safety, 23, 12-23.

https://www.researchgate.net/publication/273833894 https://doi.org/10.1016/j.jchas.2015.03.001

[21] National Research Council (2011) Prudent Practices in the Laboratory: Handling and Management of Chemical Hazards. National Academies Press, Washington DC, 17-18.

[22] Rachel, H. (2016) The Importance of a Positive Health and Safety Culture. https://www.proaktive.co.uk/blog/the-importance-of-a-positive-health-and-safety-c $\underline{\text { ulture }}$

[23] New South Wales Government (2018) Safety Culture Survey: Questionnaire NSW. https://www.health.nsw.gov.au

[24] Flin, R., Mearns, K. and Burns, C. (2004) Hospital Safety Climate Scale. University of Aberdeen, Aberdeen.

[25] Guldenmund, W.F. (2007) The Use of Questionnaires in Safety Culture ResearchAn Evaluation. Journal of Safety Science, 45, 723-743. 
https://doi.org/10.1016/j.ssci.2007.04.006

[26] European Occupational Safety and Health Administration (2010) European Agency for Safety and Health at Work.

https://osha.europa.eu/en/toolsandpublications/publications/reports/culture_assess $\underline{\text { ment_soar }}$

[27] Gibson, J.H., Schroder, I. and Wayne, N.L. (2014) A Research University's Rapid Response to a Fatal Chemistry Accident: Safety Changes and Outcomes. Journal of Chemical Health and Safety, 21, 18-26. https://doi.org/10.1016/j.jchas.2014.01.003

[28] International Organization for Standardization (2018) ISO 45001-Occupational Health and Safety.

https://www.iso.org/iso-45001-occupational-health-and-safety.html 